\title{
Alcohol state-dependent cues in avoidance learning
}

\author{
LOWELL T. CROW and CHARLES H. WATKINS \\ Western Washington State College, Bellingham, Washington 98225
}

\begin{abstract}
Rats trained under alcohol in shuttlebox avoidance responding showed decrements in retention $24 \mathrm{~h}$ later when compared to controls or to animals given pyrazole prior to the alcohol treatments. Since pyrazole inhibits alcohol oxidation, the results were interpreted in support of the notion of cue properties of alcohol as a basis for asymmetrical dissociation.
\end{abstract}

Alcohol is known to exert a state-dependent or dissociative effect upon behavior in that memory of events under sober or alcohol conditions is impaired if recall is required under a different state (Crow, 1966; Overton, 1966). This dissociation may be symmetrical or asymmetrical. In the latter case, memory under the alcohol state of events learned while sober is disrupted less than memory in the sober state of events learned under alcohol. Such asymmetry of dissociation may be due to a combination of two distinctive drug effects upon memory: impairment associated with learning in the drug state and impairment associated with recall in the drug state. A differential assessment of the two kinds of impairment is difficult in the traditional design.

Pyrazole inhibits the oxidation of ethanol and thus prolongs the presence of alcoholic blood levels and consequent intoxication (Crow, Edelbrock, \& Martin, 1975; Goldberg \& Rydberg, 1969). To the extent that the presence of alcohol acts as a cue in the sober recall of alcohol-related learning, prior pyrazole treatments should aid that recall. To the extent that such sober recall is influenced by acquisitional impairment due to alcohol, pyrazole-alcohol treatments should be detrimental.

\section{METHODS}

\section{Subjects}

Thirty-six albino (Holtzman) and 38 hooded (Long-Evans) rats were used as subjects. Eight of the $\mathbf{7 4}$ animals were female. All were naive to avoidance conditioning.

\begin{abstract}
Apparatus
The avoidance conditioning was carried out in sessions of $30 \mathrm{~min}$ duration for 30 trials at an intertrial interval of $30 \mathrm{sec}$ using a 5-sec interstimulus interval. A training session followed $24 \mathrm{~h}$ later by a testing session was carried out with four groups of animals. The alcohol group (/A) was trained under alcohol $(2.5 \mathrm{~g} / \mathrm{kg})$ and tested under placebo conditions. The pyrazole-alcohol group (PA) was trained under alcohol after a $24 \mathrm{~h}$ prior pyrazole injection $(4.3 \mathrm{mmole} / \mathrm{kg})$, and tested under placebo conditions. A saline control group $(/ /)$ was trained and tested under placebo conditions, and a pyrazole control group $(\mathrm{P} /)$ was trained and tested under
\end{abstract}

Parts of this paper were presented at the meetings of the Psychonomic Society, Boston, 1974. placebo conditions after the 24-h-prior pyrazole injection. Alcohol and placebo injections were given $10 \mathrm{~min}$ before the particular session.

\section{RESULTS}

No significant strain or sex differences were noted, and the data were pooled within the four groups. Percent avoidance responses (CAR) were noted in the training and testing sessions (Figure 1), and percent change scores were obtained. The results using the latter scores are summarized in Figure 2.

The alcohol group differs significantly from the pyrazole-alcohol group $(t=1.73, \mathrm{df}=36)$, from the saline control group $(t=3.87, \mathrm{df}=33)$, and from the pyrazole control group $(t=2.97, \mathrm{df}=37)$. No other single group comparisons were significant, but the combined alcohol-related groups (/A and PA) differ significantly from the combined control groups $(\mathrm{t}=10.62, \mathrm{df}=72)$.

\section{DISCUSSION}

The data appear to support the contention that a significant feature of the disruption in sober recall of the rat's shuttlebox avoidance learning under alcohol is the lack of alcohol in the testing session vis-à-vis the presence of alochol in the training session. The data appear consistent with those studies indicating state dependent efects which support a memory retrieval failure as

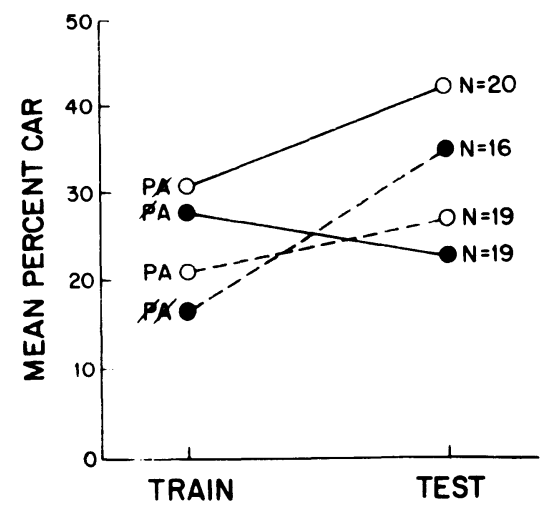

Figure 1. Mean percent avoidances for the four pyrazole (P) and alcohol (A) sequences. 


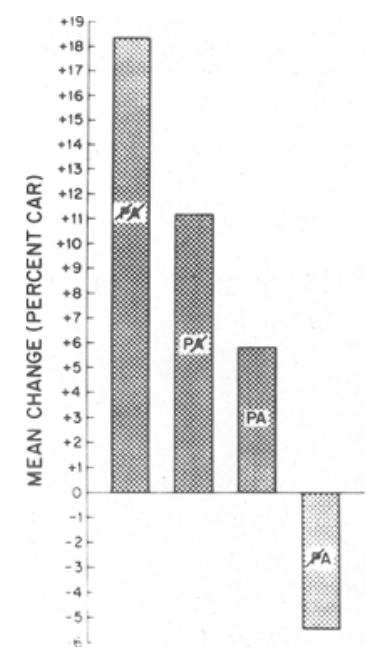

Figure 2. Percent change scores of the data presented in Figure 1.

opposed to a memory storage impairment hypothesis (Wright, Note 1).

Since alcohol is known to produce potentially discriminable cues (Barry. 1968). however. some part of the impairment noted here may be due to a generalization decrement in some undetermined alcohol-induced stimulus. That part of the alcohol cue system may be involved with autonomic changes was suggested earlier (Crow \& Ball. in press). In the shuttlebox avoidance situation, if alcohol interferes with the normal course of habituation of incompatible orienting responses, asymmetry would be expected. That is, there should be a greater decrement in the alcohol to sober change sequence than for the sober to alcohol change sequence.

\section{REFERENCE NOTE}

1. Wright, D. Differentiating stimulus and storage hypotheses of state-dependent learning. Presented at the Federation of American Societies for Experimental Biology, Atlantic City, 1972.

\section{REFERENCES}

BARRY, H. Prolonged measurement of discrimination between alcohol and non-drug states. Journal of Comparative and Physiological Psychology, 1968, 65. 349-352.

Crow, L. The effects of alcohol on conditioned avoidance responding. Physiology and Behavior, 1966, 1, 89-91.

Crow, L., \& BaLl, C. Alcohol state-dependency and autonomic reactivity. Psychophysiology (in press).

Crow, L.. Edelbrock, C.. \& Martin, P. The extension of alcohol-induced behavioral deficits with pyrazole. Physiological Psychology, 1975, 3, 56-58.

GolDBERG, L., \& RYDBERG, U. Inhibition of ethanol metabolism in vivo by administration of pyrazole. Biochemical Pharmacology, 1969, 18, 1949.

Overton. D. State dependent learning produced by depressant and atropine-like drugs. Psychopharmacologia (Berl.), 1966. 10. 31 .

(Received for publication November 11, 1975.) 